\title{
Theoretical and Experimental Studies on the Corrosion Inhibition Potentials of Two Tetrakis Pyrazole Derivatives for Mild Steel in 1.0 M HCl
}

\author{
Y.E. Louadi, ${ }^{a}$ F. Abrigach,${ }^{a}$ A. Bouyanzer, ${ }^{a}$ R. Touzani,${ }^{a, b}$ A. El Assyry, ${ }^{c}$ \\ A. Zarrouk, ${ }^{a, *}$ B. Hammouti ${ }^{a}$ \\ ${ }^{a}$ LCAE-URAC18, Faculty of Science, Mohammed First University, P.O. Box 717, \\ 60000 Oujda, Morocco \\ ${ }^{b}$ Faculté Pluridisciplinaire de Nador, Université Mohammed Premier, BP: 300, Selouane \\ 62700, Nador, Morocco \\ ${ }^{c}$ Laboratoire d'Optoélectronique et de Physico-chimie des Matériaux, (Unité associée au \\ CNRST), Université Ibn Tofail, Faculté des Sciences, B.P. 133, Kénitra, Morocco
}

Received June 30, 2016; accepted December 27, 2016

\begin{abstract}
The inhibition performance and mechanism of $\mathrm{N}^{1}, \mathrm{~N}^{1}, \mathrm{~N}^{3}, \mathrm{~N}^{3}$-tetrakis $((3,5$-dimethyl-1Hpyrazol-1-yl)methyl)propane-1,3-diamine (BF2) and $\mathrm{N}^{1}, \mathrm{~N}^{1}, \mathrm{~N}^{2}, \mathrm{~N}^{2}$-tetrakis $((3,5$-dimethyl-1H-pyrazol-1-yl)methyl) benzene-1,2-diamine (BF4) for the corrosion of mild steel in $1.0 \mathrm{M} \mathrm{HCl}$ were investigated using weight loss method and electrochemical measurements. The results show that both tetrakis pyrazole derivatives act as good inhibitors, and inhibition efficiency follows the order: BF4 > BF2. Two tetrakis pyrazole derivatives are mixed type inhibitors exhibiting predominantly cathodic behavior. The Nyquist plots showed that, after increasing inhibitors' concentrations, charge-transfer resistance increased and double-layer capacitance decreased, involving increased inhibition efficiency. The adsorption of both inhibitors on a steel surface obeyed Langmuir model, thus, the thermodynamic and kinetic parameters were calculated and discussed. Quantum chemical parameters are calculated using the Density Functional Theory method (DFT). Correlation between theoretical and experimental results is discussed.
\end{abstract}

Keywords: Mild steel; corrosion inhibition; weight loss; electrochemical techniques; DFT.

\section{Introduction}

Acid solutions are widely used in industry, such as acid pickling, industrial acid cleaning, acid descaling and oil-well cleaning [1]. As the most effective and economic method [2,3], inhibitors are applied in these processes to control the metal dissolution. Most of the well known acid inhibitors are organic compounds

\footnotetext{
*Corresponding author. E-mail address: azarrouk@gmail.com
} 
containing nitrogen, sulphur and oxygen atoms [4-10]. The efficiency of these compounds mainly depends on their abilities to be adsorbed on the metal surface with the polar groups acting as reactive centers.

The corrosion inhibition is a surface process, which involves adsorption of the organic compounds on a metal surface. The adsorption mainly depends on the electronic structure of the molecule [11]. The inhibition efficiency of organic compounds depends on the mode of interaction with the metal surface and molecular structure.

Among numerous inhibitors, $\mathrm{N}$-heterocyclic compounds are considered to be the most effective corrosion inhibitors [12]. Up to now, various $\mathrm{N}$-heterocyclic compounds are reported as good corrosion inhibitors for steel in acidic media, such as triazole derivatives [13-15], pyrazole derivatives [16-19], and bipyrazole derivatives [20-23].

In continuation of our research for developing efficient corrosion inhibitors, [2429] this work represents a systematic study of the corrosion inhibition effect of synthesized pyrazole derivatives, namely N1,N1,N3,N3-tetrakis((3,5-dimethyl1H-pyrazol-1-yl)methyl)propane-1,3-diamine (BF2) and N1,N1,N2,N2-tetrakis ((3,5-dimethyl-1H-pyrazol-1-yl)methyl)benzene-1,2-diamine (BF4), on MS in a $1.0 \mathrm{M} \mathrm{HCl}$ solution using weight loss measurement, potentiodynamic polarization, electrochemical impedance, and quantum chemical calculations. Fig. 1 shows all molecular structures used.
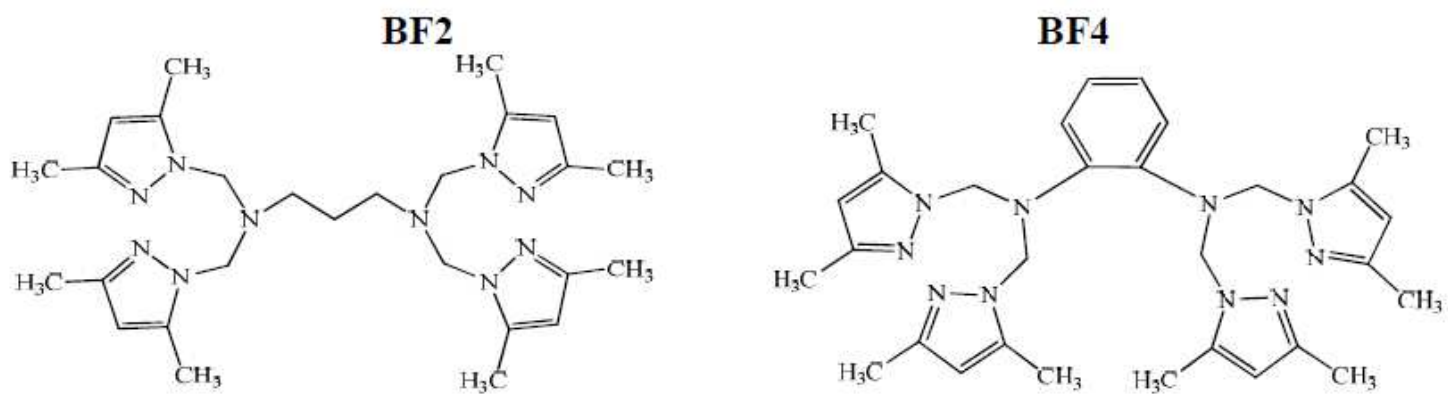

Figure 1. Chemical molecular structures of tetrakis pyrazole derivatives.

\section{Experimental}

\section{Materials}

The steel used in this study is a mild steel with a chemical composition (in wt $\%$ ) of $0.09 \% \mathrm{P}, 0.01 \% \mathrm{Al}, 0.38 \% \mathrm{Si}, 0.05 \% \mathrm{Mn}, 0.21 \% \mathrm{C}, 0.05 \% \mathrm{~S}$ and the remainder iron $(\mathrm{Fe})$. The steel samples were pre-treated prior to the experiments by grinding with emery paper (SiC) $(220,400,800,1000$ and 1200), rinsed with distilled water, degreased in acetone, washed again with bidistilled water and then dried at room temperature before use.

\section{Solutions}

The aggressive solutions of $1.0 \mathrm{M} \mathrm{HCl}$ were prepared by dilution of analytical grade $37 \% \mathrm{HCl}$ with distilled water. The concentration range of N1,N1,N3,N3tetrakis((3,5-dimethyl-1H-pyrazol-1-yl)methyl)propane-1,3-diamine (BF2) and 
N1,N1,N2,N2-tetrakis((3,5-dimethyl-1H-pyrazol-1-yl)methyl) benzene-1,2 diamine (BF4) used was $10^{-5} \mathrm{M}$ to $10^{-3} \mathrm{M}$.

\section{Gravimetric study}

Gravimetric experiments were performed according to the standard methods [30]; the mild steel sheets of $1 \times 1 \times 0.1 \mathrm{~cm}$ were abraded with a series of emery papers, $(\mathrm{SiC})(120,600$ and 1200), and then washed with distilled water and acetone. After accurate weighing, the specimens were immersed in a $100 \mathrm{~mL}$ beaker containing $250 \mathrm{~mL}$ of a $1.0 \mathrm{M} \mathrm{HCl}$ solution with and without addition of different concentrations of inhibitor. All the aggressive acid solutions were open to air. After $6 \mathrm{~h}$ of acid immersion, the specimens were taken out, washed, dried, and accurately weighed. In order to get good reproducibility, all measurements were performed a few times, and average values were reported to obtain good reproducibility. The inhibition efficiency $\left(\eta_{\mathrm{WL}} \%\right)$ and surface coverage $(\theta)$ were calculated as follows:

$$
\begin{aligned}
& C_{\mathrm{R}}=\frac{W_{\mathrm{b}}-W_{\mathrm{a}}}{A t} \\
& \eta_{\mathrm{wL}}(\%)=\left(1-\frac{w_{\mathrm{i}}}{w_{0}}\right) \times 100 \\
& \theta=1-\frac{w_{\mathrm{i}}}{w_{0}}
\end{aligned}
$$

where $W_{\mathrm{b}}$ and $W_{\mathrm{a}}$ are the specimen weight before and after immersion in the tested solution; $w_{0}$ and $w_{\mathrm{i}}$ are the values of corrosion weight losses of mild steel in uninhibited and inhibited solutions, respectively; $A$ is the total area of the mild steel specimen $\left(\mathrm{cm}^{2}\right)$; and $t$ is the exposure time $(\mathrm{h})$.

\section{Electrochemical measurements}

The electrochemical measurements were carried out using a Volta lab (TacusselRadiometer PGZ 100) potentiostat, and controlled by Tacussel corrosion analysis software model (Voltamaster 4) under static condition. The corrosion cell used had three electrodes. The reference electrode was a saturated calomel electrode (SCE). A platinum electrode was used as auxiliary electrode with a surface area of $1 \mathrm{~cm}^{2}$. The working electrode was mild steel with a surface of $1.0 \mathrm{~cm}^{2}$. All potentials given in this study were referred to this electrode. The working electrode was immersed in a test solution for $30 \mathrm{~min}$ to establish a steady state open circuit potential $\left(E_{\mathrm{ocp}}\right)$. After measuring the $E_{\mathrm{ocp}}$, the electrochemical measurements were performed. All electrochemical tests were performed in aerated solutions at $308 \mathrm{~K}$. The EIS experiments were conducted in the frequency range with a high limit of $100 \mathrm{kHz}$ and a different low limit of $0.1 \mathrm{~Hz}$ at open circuit potential, with 10 points per decade, at the rest potential, after $30 \mathrm{~min}$ of acid immersion, by applying $10 \mathrm{mV}$ ac at voltage peak-to-peak. Nyquist plots were made from these experiments. The best semicircle can be fit through the 
data points in the Nyquist plot using a non-linear least square fit, so as to give the intersections with the $x$-axis.

The inhibition efficiency of the inhibitor was calculated from the charge transfer resistance values using the following equation:

$$
\eta_{z} \%=\frac{R_{c t}^{i}-R_{c t}^{\circ}}{R_{c t}^{i}} \times 100
$$

where, $\mathrm{R}_{\text {ct }}^{\circ}$ and $\mathrm{R}_{\text {ct }}^{\mathrm{i}}$ are the charge transfer resistance in absence and in presence of the inhibitor, respectively.

After ac impedance test, the potentiodynamic polarization measurements of mild steel substrate in inhibited and uninhibited solution were scanned from cathodic to anodic direction, with a scan rate of $0.5 \mathrm{mV} \mathrm{s}^{-1}$. The potentiodynamic data were analysed using the polarization VoltaMaster 4 software. The linear Tafel segments of anodic and cathodic curves were extrapolated to corrosion potential, to obtain corrosion current densities $\left(I_{\text {corr }}\right)$. From the obtained polarization curves, the corrosion current $\left(I_{\text {corr }}\right)$ was calculated by curve fitting using the equation:

$$
I=I_{c o r r}\left[\exp \left(\frac{2.3 \Delta E}{\beta_{a}}\right)-\exp \left(\frac{2.3 \Delta E}{\beta_{c}}\right)\right]
$$

The inhibition efficiency was evaluated from the measured $I_{\text {corr }}$ values using the following relationship:

$$
\eta_{\text {Tafel }}(\%)=\frac{I_{\text {corr }}-I_{\text {corr(i) }}}{I_{\text {corr }}} \times 100
$$

where $I_{\text {corr }}$ and $I_{\text {corr(i) }}$ are the corrosion current densities for steel electrode in the uninhibited and inhibited solutions, respectively.

\section{Quantum chemical calculations}

Complete geometry optimization of the inhibitor molecules was performed using density functional theory (DFT) with Beck's three-parameter exchange functional along with LeeeYangeParr non-local correlation functional (B3LYP) with 6-1G* basis set using the Gaussian 03 programme package [31]. Frontier molecular orbitals (HOMO and LUMO) were used to interpret the adsorption of inhibitor molecules on the metal surface. According to DFT-Koopman's theorem [32,33], the ionization potential (I) is approximated as the negative of the highest occupied molecular orbital energy $\left(\mathrm{E}_{\mathrm{HOMO}}\right)$ and the negative of the lowest unoccupied molecular orbital energy $\left(\mathrm{E}_{\mathrm{LUMO}}\right)$ are related to the electron affinity (A).

$$
\begin{gathered}
\mathrm{I}=-\mathrm{E}_{\text {HOMO }} \\
\mathrm{A}=-\mathrm{E}_{\text {LUMO }}
\end{gathered}
$$

Natural bond orbital (NBO) analysis [34] was performed to evaluate the electron density distributions. The electron density plays an important role in calculating 
the chemical reactivity parameters. The global reactivities include electronegativity $(\chi)$, global hardness $(\eta)$ and global softness $(\sigma)$. They can be calculated from the following equations:

$$
\begin{aligned}
& \chi=\frac{I+A}{2} \\
& \eta=\frac{I-A}{2} \\
& \sigma=\frac{1}{\eta}=-\frac{2}{E_{\text {номо }}-E_{\text {LUмо }}}
\end{aligned}
$$

The local reactivity has been analyzed by means of Fukui indices [35], an indication of the reactive centers within the molecules. These are measurements of the chemical reactivity, as well as an indicative of the reactive regions, nucleophilic and electrophilic behavior of the molecule [36]. The condensed Fukui functions were found by taking the finite difference approximations from Mulliken population analysis of atoms in inhibitor molecules, depending on the direction of the electron transfer.

$$
\begin{aligned}
& f_{k}^{+}=q_{k}(N+1)-q_{k}(N) \\
& f_{k}^{-}=q_{k}(N)-q_{k}(N-1)
\end{aligned}
$$

where $\mathrm{q}(\mathrm{N}), \mathrm{q}(\mathrm{N}+1)$, and $\mathrm{q}(\mathrm{N}-1)$ are the electronic population of the atom $\mathrm{k}$ in neutral, cationic and anionic systems, respectively [37].

\section{Results and discussion}

\section{Potentiodynamic polarization curves}

The potentiodynamic measurement results of mild steel in a $1.0 \mathrm{M} \mathrm{HCl}$ solution, without and with different range of inhibitors concentrations, were shown in Fig. $2 \mathrm{a}$ and $\mathrm{b}$. The polarization parameters, namely corrosion current density ( $\left.\mathrm{I}_{\text {corr }}\right)$, corrosion potential $\left(\mathrm{E}_{\mathrm{corr}}\right)$, anodic Tafel slope $\left(\beta_{\mathrm{a}}\right)$, cathodic Tafel slope $\left(\beta_{\mathrm{c}}\right)$ and percentage inhibition efficiency $\left(\eta_{\text {Tafel }} \%\right)$ were calculated from the Tafel curves and are given in Table 1. From Fig. 2 it can be observed that both the cathodic and anodic reactions were suppressed with the addition of inhibitor, which suggested that the tetrakis pyrazole derivatives reduced anodic dissolution and also retarded the hydrogen evolution reaction [38].

It is observed that the corrosion potentials $\left(\mathrm{E}_{\mathrm{corr}}\right)$ for mild steel in the presence of BF2 (Fig. 2a) and BF4 (Fig. 2b) are slightly shifted towards the positive potentials compared with the mild steel in $1.0 \mathrm{M} \mathrm{HCl}$. Both anodic and cathodic current densities were reduced in the presence of BF2 and BF4, which suggests a mixed-type inhibitor behavior [39].

It is clear from Table 1 that, after increasing the concentration of inhibitor, the inhibition efficiency increased, while the corrosion current density decreased due to adsorption of $\mathrm{BF} 2$ and $\mathrm{BF} 4$ on the mild steel surface. The minor shift in $\mathrm{E}_{\mathrm{corr}}$ value $(10 \mathrm{mV})$ towards positive direction in the presence of inhibitors, as 
compared to the $\mathrm{E}_{\text {corr }}$ value in the absence of inhibitor, indicates that BF2 and $\mathrm{BF} 4$ act as a mixed type inhibitor with predominant control of the anodic reaction [40]. From Table 1, it is observed that inhibition efficiency increased with an increased concentration of the two tetrakis pyrazole derivatives. Also, the order of corrosion inhibition efficiency for the highest concentration $\left(10^{-3} \mathrm{M}\right)$ of the two studied inhibitors is BF4 $(94.2 \%)>\mathrm{BF} 2(87.0 \%)$.
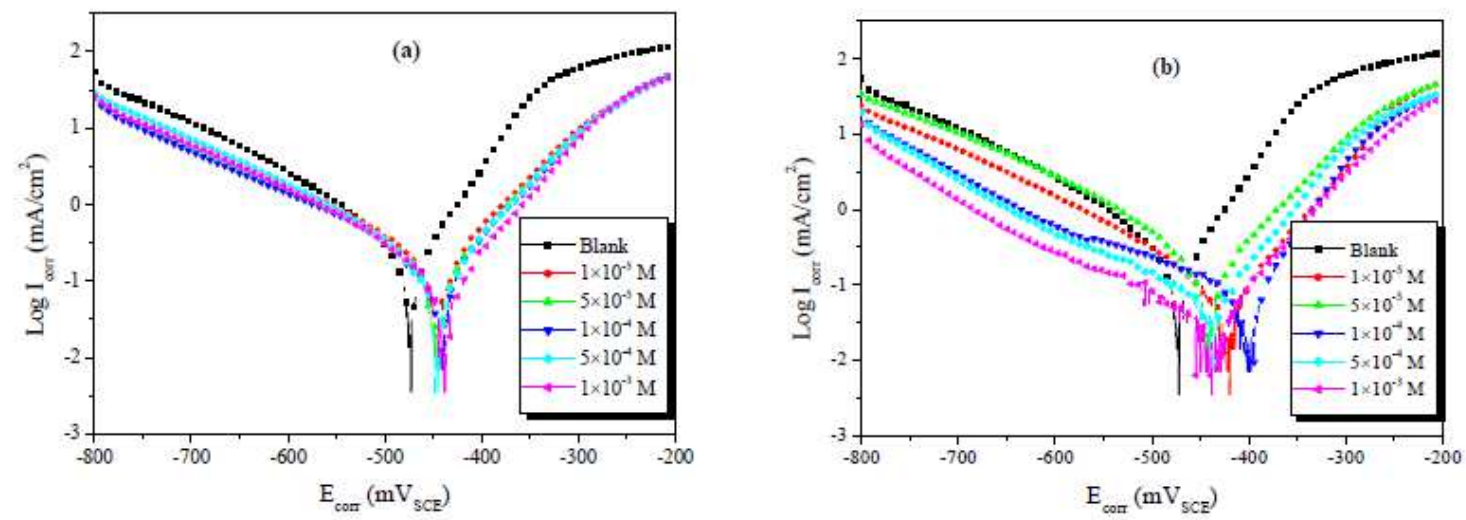

Figure 2. Polarization curves for mild steel in $1.0 \mathrm{M} \mathrm{HCl}$ in the presence and absence of different concentration of (a) N1,N1,N3,N3-tetrakis((3,5-dimethyl-1H-pyrazol-1yl)methyl)propane-1,3-diamine (BF2), and (b) N1,N1,N2,N2-tetrakis((3,5-dimethyl1H-pyrazol-1-yl)methyl)benzene-1,2-diamine (BF4).

Table 1. Electrochemical parameters for mild steel in a $1.0 \mathrm{M} \mathrm{HCl}$ solution without and with different concentrations of tetrakis pyrazole derivatives at $308 \mathrm{~K}$.

\begin{tabular}{|c|c|c|c|c|c|c|c|}
\hline Inhibitor & $\begin{array}{c}\text { Conc } \\
(\mathrm{M})\end{array}$ & $\begin{array}{c}-\mathbf{E}_{\text {corr }} \\
\left(\mathrm{mV} V_{\text {SCE }}\right)\end{array}$ & $\begin{array}{c}-\beta_{\mathrm{a}} \\
\left(\mathrm{mV} \mathbf{d e c}^{-1}\right)\end{array}$ & $\begin{array}{c}-\beta_{\mathrm{c}} \\
\left(\mathrm{mV} \operatorname{dec}^{-1}\right)\end{array}$ & $\begin{array}{c}I_{\text {corr }} \\
\left(\mu \mathrm{A} \mathrm{cm}^{-2}\right)\end{array}$ & $\begin{array}{c}\eta_{\text {Tafel }} \\
(\%)\end{array}$ & $\boldsymbol{\theta}$ \\
\hline $\mathrm{HCl}$ & 1.0 & 450 & 67.1 & 144.2 & 361.8 & - & - \\
\hline \multirow{5}{*}{ BF2 } & $1 \times 10^{-5}$ & 440 & 78.7 & 113.4 & 133.7 & 66.8 & 0.668 \\
\hline & $5 \times 10^{-5}$ & 444 & 77.8 & 124.2 & 118.1 & 73.7 & 0.737 \\
\hline & $1 \times 10^{-4}$ & 444 & 73.0 & 124.3 & 102.5 & 74.8 & 0.748 \\
\hline & $5 \times 10^{-4}$ & 442 & 70.5 & 105.2 & 79.4 & 79.3 & 0.793 \\
\hline & $1 \times 10^{-3}$ & 440 & 66.2 & 100.3 & 59.2 & 87.0 & 0.870 \\
\hline \multirow{5}{*}{ BF4 } & $1 \times 10^{-5}$ & 444 & 73.7 & 155.8 & 109.3 & 69.8 & 0.698 \\
\hline & $5 \times 10^{-5}$ & 446 & 72.8 & 90.8 & 96.7 & 73.3 & 0.733 \\
\hline & $1 \times 10^{-4}$ & 446 & 51.1 & 143.7 & 46.8 & 87.1 & 0.871 \\
\hline & $5 \times 10^{-4}$ & 444 & 58.7 & 151.8 & 37.1 & 89.7 & 0.897 \\
\hline & $1 \times 10^{-3}$ & 446 & 64.6 & 155.2 & 21.1 & 94.2 & 0.942 \\
\hline
\end{tabular}

\section{Electrochemical impedance spectroscopy studies}

The Nyquist plots obtained from the EIS measurements for mild steel in $1.0 \mathrm{M}$ $\mathrm{HCl}$ solutions at $308 \mathrm{~K}$ are shown in Fig. 3. The plots are characterized by a semicircle, which means the process was mainly controlled by capacitance and depressed semicircle, reflecting the surface in-homogeneity of structural or interfacial origin, such as that found in adsorption processes [41]. The capacitive semicircle refers to the double layer capacitance and transfer resistance $\left(R_{c t}\right)$. Different size semicircles are shown in Fig. 3. The diameter of the semicircle represents the value of transfer resistance $\left(R_{c t}\right)$, which indicates a decreasing trend in corrosion rate. The charge transfer resistance values $\left(R_{c t}\right)$ were calculated 
from the difference between impedance values at lower and higher frequencies, as suggested by Haruyama et al. [42]. The double layer capacitance $\left(\mathrm{C}_{\mathrm{dl}}\right)$ was obtained from the following equation [43]:

$$
f\left(-Z_{\text {img }}\right)=\frac{1}{2 \pi C_{d l} R_{c t}}
$$

where $\mathrm{Z}_{\mathrm{img}}$ is the frequency of maximum imaginary components of the impedance and $R_{c t}$ is the charge transfer resistances.
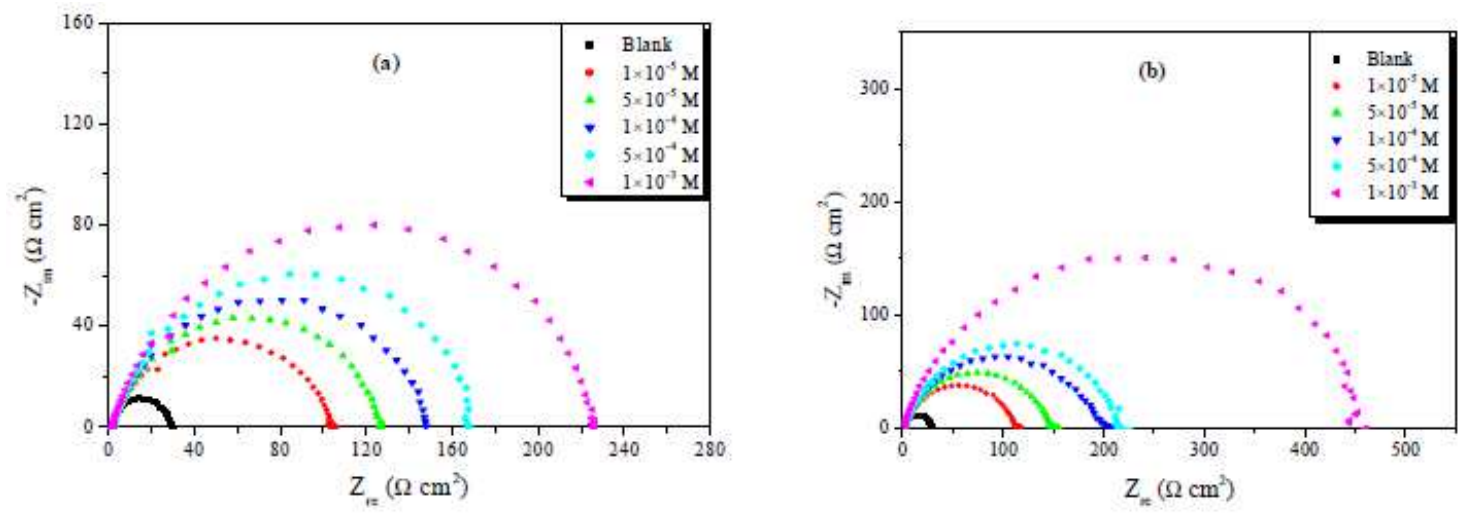

Figure 3. Nyquist plots recorded for mild steel in $1.0 \mathrm{M} \mathrm{HCl}$ solutions without and with different concentrations of (a) BF2 and (b) BF4.

The calculated electrochemical parameters of EIS measurements are listed in Table 2. From the electrochemical impedance parameters and the inhibition efficiency $\left(\eta_{\mathrm{z}} \%\right)$, which are listed in Table 2 , it is clear that the impedance spectra exhibit one single capacitive loop, indicating that: (i) the charge transfer takes place at the electrode/solution interface, (ii) the transfer process controls corrosion reaction, and (iii) the presence of the inhibitor does not change the mechanism of steel dissolution [44].

As the inhibitor concentration increased, the $R_{c t}$ values increased and the $C_{d l}$ values tended to decrease due to a decrease in local dielectric constant and/or an increase in the thickness of the electrical double layer, suggesting that the inhibitor molecules acted by adsorption at the metal/solution interface. Addition of synthesized inhibitors provided lower $\mathrm{C}_{\mathrm{dl}}$ values, probably due to the replacement of water molecules by the inhibitor molecule at the electrode surface. In addition, the inhibitor molecules may reduce the capacitance by increasing the double layer thickness, according to the Helmholtz model [45]:

$$
\delta_{\text {org }}=\frac{\varepsilon_{0} \varepsilon A}{C_{d l}}
$$

where $\varepsilon$ is the dielectric constant of the medium, $\varepsilon_{0}$ is the vacuum permittivity, A is the electrode surface area and $\delta_{\text {org }}$ is the thickness of the protective layer.

The order of tetrakis pyrazole derivatives remains unchanged; it is as follows: BF4 > BF2. This is also in agreement with the observed order of corrosion inhibition obtained from potentiodynamic measurements. 
Table 2. EIS parameters for the corrosion of mild steel in $1.0 \mathrm{M} \mathrm{HCl}$ containing BF2 and BF4 at $308 \mathrm{~K}$.

\begin{tabular}{ccccccc}
\hline Inhibitor & $\begin{array}{c}\text { Conc } \\
(\mathbf{M})\end{array}$ & $\begin{array}{c}\mathbf{R}_{\mathbf{c t}} \\
\left(\mathbf{\Omega} \mathbf{~ c m}^{2}\right)\end{array}$ & $\begin{array}{c}\mathbf{f}_{\mathbf{m a x}} \\
(\mathbf{H z})\end{array}$ & $\begin{array}{c}\mathbf{C}_{\mathbf{d l}} \\
\left(\boldsymbol{\mu} \mathbf{F} \mathbf{~ c m}^{-2}\right)\end{array}$ & $\begin{array}{c}\eta_{\mathbf{z}} \\
(\boldsymbol{\%})\end{array}$ & $\boldsymbol{\theta}$ \\
\hline $\mathrm{HCl}$ & 1.0 & 27.4 & 100 & 58.0 & - & - \\
\hline \multirow{3}{*}{$\mathrm{BF} 2$} & $1 \times 10^{-5}$ & 102.8 & 31.6 & 48.9 & 73.3 & 0.733 \\
\cline { 2 - 7 } & $5 \times 10^{-5}$ & 125.9 & 31.6 & 39.9 & 78.2 & 0.782 \\
\cline { 2 - 7 } & $1 \times 10^{-4}$ & 148.4 & 31.6 & 33.9 & 81.5 & 0.815 \\
\cline { 2 - 7 } & $5 \times 10^{-4}$ & 170.5 & 31.6 & 29.5 & 83.9 & 0.839 \\
\cline { 2 - 7 } & $1 \times 10^{-3}$ & 226.7 & 25.0 & 28.1 & 87.9 & 0.879 \\
\hline \multirow{3}{*}{ BF4 } & $1 \times 10^{-5}$ & 110.8 & 40.0 & 35.9 & 75.2 & 0.752 \\
\cline { 2 - 7 } & $5 \times 10^{-5}$ & 145.5 & 31.6 & 34.6 & 81.1 & 0.811 \\
\cline { 2 - 7 } & $1 \times 10^{-4}$ & 194.5 & 25.0 & 32.7 & 85.9 & 0.859 \\
\cline { 2 - 7 } & $5 \times 10^{-4}$ & 215.1 & 25.0 & 29.6 & 87.2 & 0.872 \\
\cline { 2 - 7 } & $1 \times 10^{-3}$ & 473.8 & 12.5 & 26.9 & 94.2 & 0.942 \\
\hline
\end{tabular}

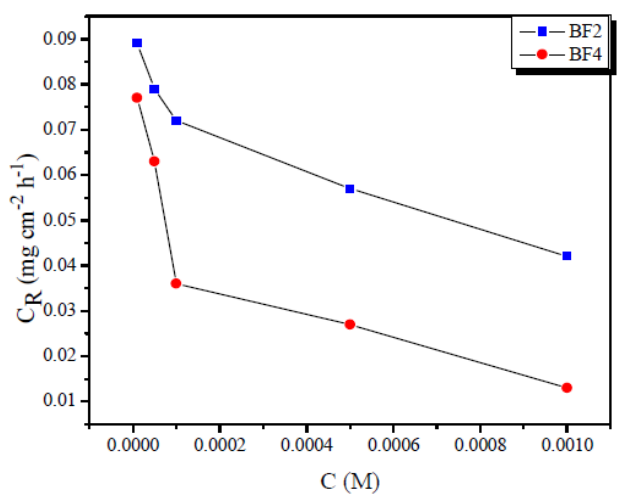

Figure 4. Relationship between corrosion rate $\left(C_{R}\right)$ and concentration of inhibitor $(C)$ in $1.0 \mathrm{M} \mathrm{HCl}$ at $308 \mathrm{~K}$ (weight loss method, immersion time is $6 \mathrm{~h}$ ).

\section{Weight loss measurements}

Effect of tetrakis pyrazole compounds on corrosion rate

Fig. 4 illustrates the corrosion rate $\left(\mathrm{C}_{\mathrm{R}}\right)$ of mild steel in $1.0 \mathrm{M} \mathrm{HCl}$ at $308 \mathrm{~K}$ in the presence of different concentrations (C) of tetrakis pyrazole compounds (immersion time is $6 \mathrm{~h}$ ). The corrosion rate reduces after addition of the selected two tetrakis pyrazole compounds, and decreases with the inhibitor concentration. This behaviour is due to the fact that the adsorption coverage increases with the increase of inhibitor's concentration, which shields the mild steel surface efficiently from the medium. In the absence of inhibitor, the corrosion rate is as high as $0.32 \mathrm{mg} \mathrm{cm}^{-2} \mathrm{~h}^{-1}$, while in the presence of $10^{-3} \mathrm{M}$ inhibitor, the corrosion rate values are reduced to 0.042 and $0.013 \mathrm{mg} \mathrm{cm}^{-2} \mathrm{~h}^{-1}$ for $\mathrm{BF} 2$ and BF4, respectively. At any given inhibitor concentration, the corrosion rate follows the order: $\mathrm{C}_{\mathrm{R}}(\mathrm{BF} 4)<\mathrm{C}_{\mathrm{R}}(\mathrm{BF} 2)$, which indicates that BF4 exhibits the best inhibitive performance among two tetrakis pyrazole compounds.

Effect of tetrakis pyrazole compounds on inhibition efficiency

Fig. 5 represents inhibition efficiency $\left(\eta_{\mathrm{WL}}\right)$ values obtained from the weight loss in $1.0 \mathrm{M} \mathrm{HCl}$ solutions in the presence of various concentrations of BF2 and BF4 at $308 \mathrm{~K}$ (immersion time is $6 \mathrm{~h}$ ). Clearly, $\eta_{w L}$ increases with an increase in the inhibitor's concentration. At $10^{-3} \mathrm{M}$, the maximum $\eta_{\mathrm{wL}}$ is $86.7 \%$ for $\mathrm{BF} 2$, and 
$95.8 \%$ for $\mathrm{BF} 4$, which indicates that two tetrakis pyrazole compounds act as good corrosion inhibitors for mild steel in $1.0 \mathrm{M} \mathrm{HCl}$. Inhibition efficiency of the examined tetrakis pyrazole compounds follows the order: BF4 > BF2.

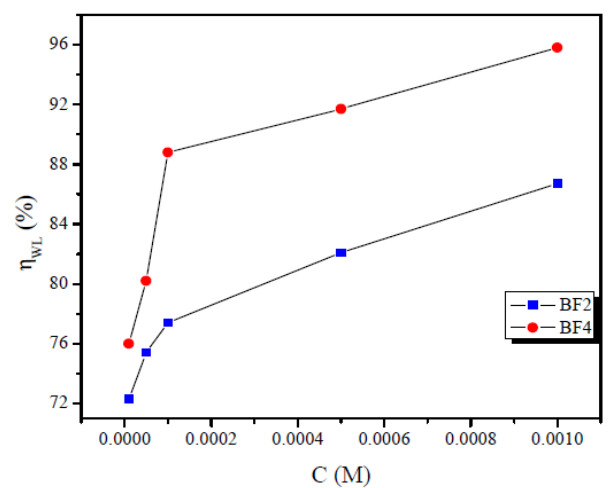

Figure 5. Relationship between inhibition efficiency $\left(\eta_{\mathrm{WL}}\right)$ and concentration of inhibitor (C) in $1.0 \mathrm{M} \mathrm{HCl}$ at $308 \mathrm{~K}$ (weight loss method, immersion time is $6 \mathrm{~h}$ ).

Effect of temperature and thermodynamic activation parameters

Being given that the temperature is one of the factors that may affect the behavior of a material in a corrosive environment, and can also modify the metalinhibitor interaction, it is essential to study the effect of this factor on the protection rates, as well as to determine the mechanism of inhibition, to calculate the activation energies of the corrosion process.

The study of the influence of temperature on the rate of corrosion inhibition of mild steel by our inhibitors was performed at temperatures 313, 323, 333 and 343 $\mathrm{K}$, in the absence and in the presence of inhibitor at $10^{-3} \mathrm{M}$. This study determines the activation energies, enthalpies and entropies of activation of the corrosion process, and thus provides information on the mechanism of inhibition. The corresponding data are shown in Table 3.

Table 3. Various corrosion parameters for steel in $1.0 \mathrm{M} \mathrm{HCl}$ in absence and presence of optimum concentration of BF2 and BF4 at different temperatures.

\begin{tabular}{ccccc}
\hline Medium & $\begin{array}{c}\text { Temp } \\
(\mathbf{K})\end{array}$ & $\begin{array}{c}\mathbf{C}_{\mathbf{R}} \\
\left(\mathbf{m g} / \mathbf{c m}^{\mathbf{2}} \mathbf{h}\right)\end{array}$ & $\boldsymbol{\theta}$ & $\begin{array}{c}\boldsymbol{\eta}_{\mathbf{W L}} \\
\mathbf{( \% )}\end{array}$ \\
\hline \multirow{3}{*}{ Blank } & 313 & 1.300 & - & - \\
& 323 & 1.828 & - & - \\
& 333 & 3.635 & - & - \\
\hline \multirow{3}{*}{ BF2 } & 343 & 6.336 & - & - \\
& 313 & 0.275 & 0.788 & 78.8 \\
& 323 & 0.476 & 0.740 & 74.0 \\
& 333 & 1.247 & 0.657 & 65.7 \\
BF4 & 343 & 2.508 & 0.604 & 60.4 \\
& 313 & 0.116 & 0.911 & 91.1 \\
& 323 & 0.237 & 0.870 & 87.0 \\
& 333 & 0.638 & 0.824 & 82.4 \\
& 343 & 1.696 & 0.732 & 73.2 \\
\hline
\end{tabular}

The comparative study of Table 3 showed that the corrosion rate increases with an increase in temperature in both the stabilized and inhibited solutions, while the inhibition efficiency of $\mathrm{BF} 2$ and $\mathrm{BF} 4$ products decreases. A decrease in the 
efficiency of inhibition with increasing temperature in the presence of our compounds may be due to the weakening of physical adsorption.

To determine the activation energy, we have used the Arrhenius equation (16) to account for the effect of temperature $(T)$ on the corrosion rate $\left(\mathrm{C}_{\mathrm{R}}\right)$. The change in the $\log$ corrosion rate, as a function of the reciprocal of the absolute temperature, is a linear function of $\mathrm{T}^{-1}$, and the corresponding relation (17) provides access to the activation energies:

$$
\begin{gathered}
C_{R}=A \exp \left(-\frac{E_{a}}{R T}\right) \\
L \mathrm{Ln} C_{R}=-\frac{E_{a}}{R T}+\operatorname{Ln} A
\end{gathered}
$$

To access the activation thermodynamic characteristics, enthalpy $\left(\Delta \mathrm{H}_{\mathrm{a}}\right)$ and entropy of activation $\left(\Delta \mathrm{S}_{\mathrm{a}}\right)$, we have used the Arrhenius equation transition [46]:

$$
C_{R}=\frac{R T}{N h} \exp \left(\frac{\Delta S_{a}}{R}\right) \exp \left(-\frac{\Delta H_{\mathrm{a}}}{R T}\right)
$$

where $C_{R}$ is the corrosion rate, $R$ the gas constant, $T$ the absolute temperature, $A$ the pre-exponential factor, $\mathrm{h}$ the Plank's constant, $\mathrm{N}$ is Avogrado's number, $\mathrm{E}_{\mathrm{a}}$ the activation energy for corrosion process, $\Delta H_{\mathrm{a}}$ the enthalpy of activation and $\Delta S_{\mathrm{a}}$ the entropy of activation.

The curves of variation of the logarithm of the corrosion rate as a function of the reciprocal of the absolute temperature $\left(\mathrm{T}^{-1}\right)$ are recorded in Fig. 6. The curves obtained in the form of lines obey the Arrhenius law, which satisfies the relation (17).

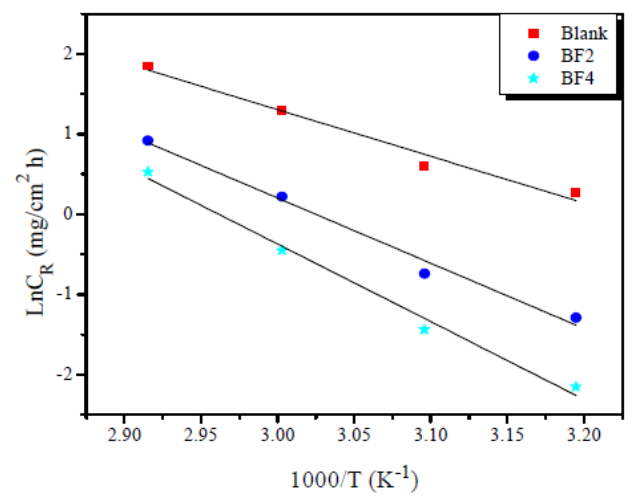

Figure 6. Arrhenius plots of $\mathrm{Ln} \mathrm{C}_{\mathrm{R}}$ vs. $1 / \mathrm{T}$ for steel in $1.0 \mathrm{M} \mathrm{HCl}$ in the absence and the presence of BF2 and BF4 at optimum concentration.

Fig. 7 shows the variation of $\operatorname{Ln}\left(\mathrm{C}_{\mathrm{R}} / \mathrm{T}\right)$ vs. $(1 / \mathrm{T})$ as a straight line with a slope of $\left(-\Delta \mathrm{H}_{\mathrm{a}} / \mathrm{R}\right)$, and the intersection with the y-axis is $\left[\mathrm{Ln}(\mathrm{R} / \mathrm{Nh})+\left(\Delta \mathrm{S}_{\mathrm{a}} / \mathrm{R}\right)\right]$. From these relationships, values of $\Delta \mathrm{S}_{\mathrm{a}}$ and $\Delta \mathrm{H}_{\mathrm{a}}$ can be calculated. The activation parameters $\left(\mathrm{E}_{\mathrm{a}}, \Delta \mathrm{H}_{\mathrm{a}}\right.$ and $\left.\Delta \mathrm{S}_{\mathrm{a}}\right)$ calculated from the slopes of Arrhenius lines in the absence and presence of our inhibitors (Fig.6 and Fig.7) are summarized in Table 4. 


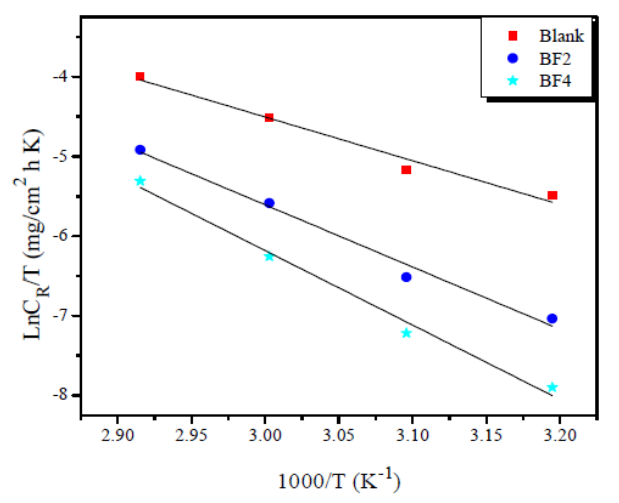

Figure 7. Arrhenius plots of $\operatorname{Ln}\left(\mathrm{C}_{\mathrm{R}} / \mathrm{T}\right)$ vs. $1 / \mathrm{T}$ for steel in $1.0 \mathrm{M} \mathrm{HCl}$ in the absence and the presence of $\mathrm{BF} 2$ and $\mathrm{BF} 4$ at optimum concentration.

Table 4. Activation parameters for the steel dissolution in $1.0 \mathrm{M} \mathrm{HCl}$ in the absence and the presence of BF2 and BF4 at $10^{-3} \mathrm{M}$.

\begin{tabular}{lcccccc}
\hline Inhibitors & $\begin{array}{c}\mathbf{A} \\
\left(\mathbf{m g} / \mathbf{c m}^{2} \mathbf{h}\right)\end{array}$ & $\mathbf{R}^{\mathbf{2}}$ & $\begin{array}{c}\mathbf{E}_{\mathbf{a}} \\
(\mathbf{K J} / \mathbf{m o l})\end{array}$ & $\begin{array}{c}\Delta \mathbf{H}_{\mathbf{a}} \\
(\mathbf{K J} / \mathbf{m o l})\end{array}$ & $\begin{array}{c}\Delta \mathbf{S}_{\mathbf{a}} \\
(\mathbf{J} / \mathbf{m o l} \mathbf{K})\end{array}$ & $\begin{array}{c}\mathbf{E}_{\mathbf{a}}-\Delta \mathbf{H}_{\mathbf{a}} \\
(\mathbf{K J} \mathbf{J} / \mathbf{m o l})\end{array}$ \\
\hline Blank & $1.4185 \times 10^{8}$ & 0.96872 & 48.40 & 45.68 & -97.95 & 2.72 \\
BF2 & $4.9161 \times 10^{10}$ & 0.98041 & 67.66 & 64.94 & -49.33 & 2.72 \\
BF4 & $2.8188 \times 10^{12}$ & 0.98570 & 80.48 & 77.76 & -15.67 & 2.72 \\
\hline
\end{tabular}

It is evident from Table 4 that the values of the apparent activation energy for the inhibited solutions were higher than those for the uninhibited solution, indicating that the dissolution of mild steel was decreased due to the formation of a barrier by the adsorption of the inhibitors on the metal surface [47].

The values of $\mathrm{E}_{\mathrm{a}}$ and $\Delta \mathrm{H}_{\mathrm{a}}$ were increased in the presence of inhibitors, suggesting that the energy barrier of the corrosion reaction increases, which means that the steel dissolution-is difficult [48]. According to Gomma et al. [49], the activation energy is much higher when the inhibitor is more effective. However, the positive sign of the endothermic enthalpy reflects the nature of steel dissolution. We note that the variation of the activation energy $E_{a}$ and the enthalpy of $\Delta \mathrm{H}_{\mathrm{a}}$ vary in the same way with the inhibitor's concentration, which satisfies the relationship between $\mathrm{E}_{\mathrm{a}}$ and thermodynamics as $\Delta \mathrm{H}_{\mathrm{a}}[50]: \mathrm{E}_{\mathrm{a}}-\Delta \mathrm{H}_{\mathrm{a}}=\mathrm{RT}$.

The values of $\Delta S_{\mathrm{a}}$ were lower for the solution without inhibitor than those for the solution with inhibitor. This may be because the rate-determining step for the activated complex was the association rather than the dissociation step [51]. As seen from Table 4 , there is a shift of $\Delta \mathrm{S}_{\mathrm{a}}$ to more positive values in the presence of the inhibitor, thus the increase in disorder is a driving force that can overcome the barriers for the inhibitor's adsorption onto the metal surface.

\section{Adsorption isotherm and thermodynamic parameters}

The adsorption isotherms are vital in elucidating the corrosion inhibition mechanism, since they express the interaction of the inhibitor molecule with the active sites on the mild steel surface. Therefore, in this study, several adsorption isotherms were evaluated, namely, Langmuir, Frumkin and Temkin. As can be seen from Fig. 8, straight lines were obtained $\left(\mathrm{R}^{2}\right.$ is almost equal to unity) by plotting $\mathrm{C} / \theta$ vs. $\mathrm{C}$ at all concentrations studied. This indicates that the inhibitor is 
adsorbed on the mild steel surface, according to the Langmuir adsorption isotherm. From the intercepts of the straight lines on the $\mathrm{C} / \theta$ axis, $\mathrm{K}_{\mathrm{ads}}$ values were calculated for the adsorption process (Table 5). The slope values are mostly equal to unity, indicating the physicochemical adsorption of inhibitor molecules on an active site on the mild steel surface. Free energy of adsorption $\left(\Delta G_{\text {ads }}^{\text {o }}\right)$ was calculated by using the following equation Eq. (19):

$$
\Delta G_{a d s}^{\circ}=-R T \operatorname{Ln}\left(55.5 K_{a d s}\right)
$$

where $\mathrm{R}$ is the gas constant, $\mathrm{T}$ is the absolute temperature of the experiment and the constant value of 55.5 is the concentration of water in a solution in $\mathrm{mol} \mathrm{L}^{-1}$.
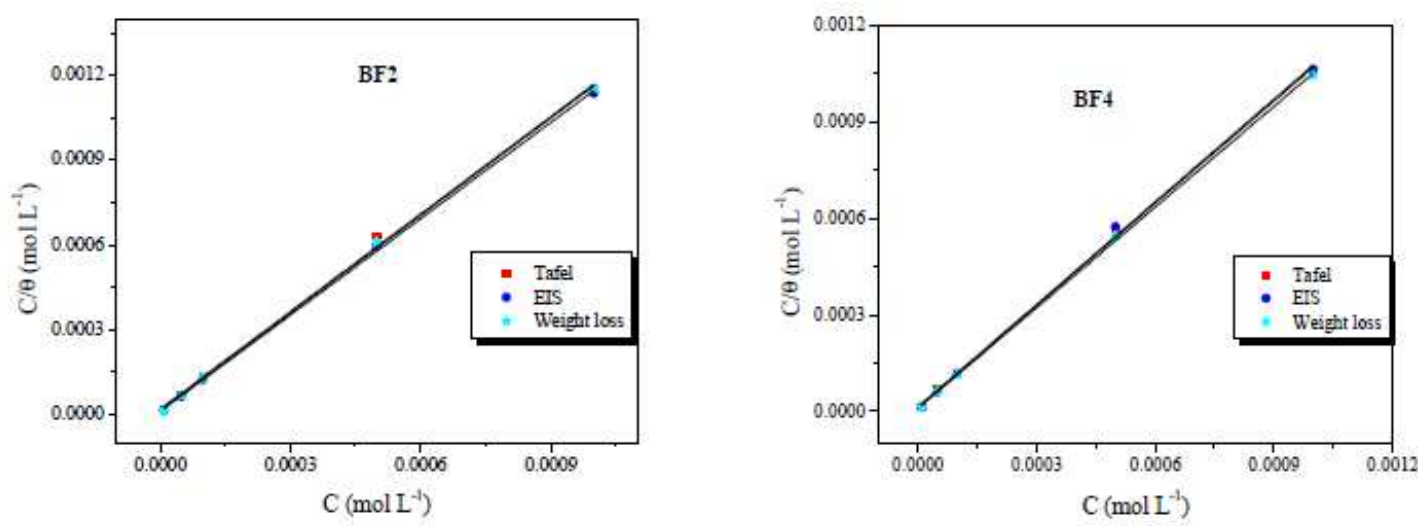

Figure 8. Langmuir adsorption isotherm for mild steel immersed in a $1.0 \mathrm{M} \mathrm{HCl}$ solution in presence of various concentrations of BF2 and BF4.

Table 5. Thermodynamic parameters for the adsorption of inhibitors in $1.0 \mathrm{M} \mathrm{HCl}$ on the mild steel at different concentrations.

\begin{tabular}{cccccc}
\hline Inhibitor & Method & $\mathbf{R}^{2}$ & Slopes & $\begin{array}{c}\mathbf{K}_{\text {ads }} \\
(\mathbf{L} / \mathbf{m o l})\end{array}$ & $\begin{array}{c}\Delta G_{a d s}^{\circ} \\
\mathbf{K J} / \mathbf{m o l})\end{array}$ \\
\hline \multirow{3}{*}{ BF2 } & Tafel & 0.99893 & 1.15 & 58066.61 & -38.37 \\
& EIS & 0.99975 & 1.14 & 108872.1 & -39.98 \\
& Weight loss & 0.99965 & 1.15 & 84232.51 & -39.33 \\
& & & & & \\
BF4 & Tafel & 0.99973 & 1.06 & 81807.62 & -39.25 \\
& EIS & 0.99927 & 1.06 & 82468.78 & -39.27 \\
& Weight loss & 0.99987 & 1.05 & 114795.8 & -40.12 \\
\hline
\end{tabular}

Table 5 shows the negative values of $\Delta G_{\text {ads }}^{\text {, }}$ indicating the spontaneity of adsorption of the inhibitor molecules on the mild steel surface [52]. In general, $\Delta G_{\text {ads }}^{\text {o }}$ values below $-20 \mathrm{~kJ} \mathrm{~mol}^{-1}$ are due to the physisorption of the inhibitor, whereas $\Delta G_{\text {ads }}^{\mathrm{o}}$ values above $-40 \mathrm{~kJ} \mathrm{~mol}^{-1}$ are attributed to the chemisorption of the inhibitor molecules on metal surface. In the present study, $\Delta G_{\text {ads }}^{\circ}$ values are between -38.27 and $-40.12 \mathrm{~kJ} \mathrm{~mol}^{-1}$, which provides evidence for both electrostatic interactions (physisorption) and charge sharing or transferring from the inhibitor to the charged mild steel surface (chemisorption) [53]. Moreover, higher values for the equilibrium constant $\left(\mathrm{K}_{\mathrm{ads}}\right)$ and standard free energy of 
adsorption ( $\Delta G_{\text {ads }}^{\mathrm{o}}$ ) support a better inhibitive activity of the substance [54]. Fig. 8 shows a skeletal representation of adsorption on the charged mild steel surface.

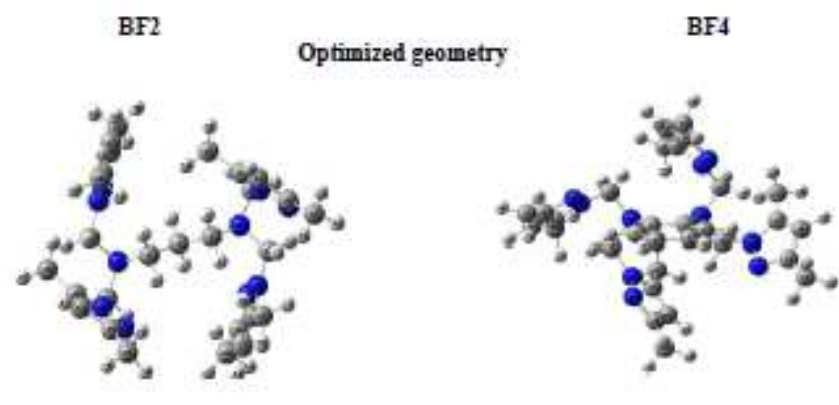

HOMO orbitals
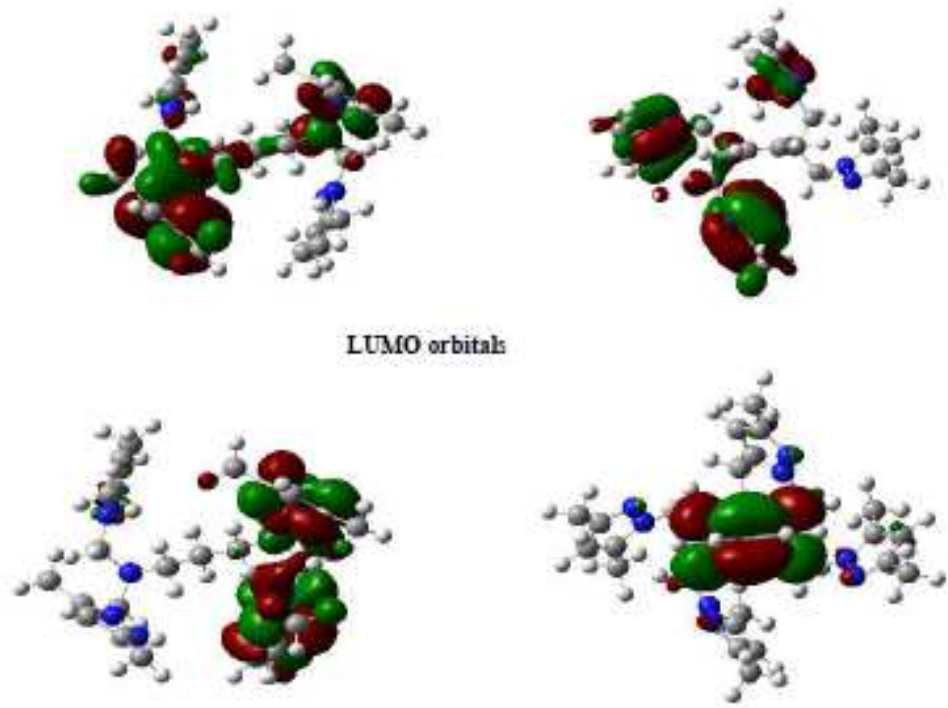

Figure 9. The optimized geometry, HOMO and LUMO orbitals of molecules BF2 and BF4 at the BLYP level.

\section{Quantum chemical calculation}

\section{Frontier orbital energies}

It is well known that the molecular reactivity is mainly analyzed via frontier orbital theory; therefore, it is necessary to investigate the highest occupied orbital (HOMO) and the lowest unoccupied orbital (LUMO) for exploring the adsorption behavior of corrosion inhibitor on the metal surface. The HOMO and LUMO of BF2 and BF4 molecules were calculated and are presented in Fig. 9.

The quantum-chemical parameters related to the BF2 and BF4 molecules are listed in Table 6. They include: $\mathrm{E}_{\text {Hомо }}$, ELumo, the energy gap $(\Delta \mathrm{E})$, dipole moment $(\mu)$, the chemical potential, global hardness $(\sigma)$ and global softness $(S)$.

Table 6. Computed molecular parameters for BF2 and BF4 compounds.

\begin{tabular}{ccccccc}
\hline & $\begin{array}{c}E_{\text {HOMO }} \\
(\mathbf{e V})\end{array}$ & $\begin{array}{c}E_{\text {LUMO }} \\
(\mathbf{e V})\end{array}$ & $\begin{array}{c}\Delta E \\
(\mathbf{e V})\end{array}$ & $\begin{array}{c}\boldsymbol{\mu} \\
(\mathbf{D e b y e})\end{array}$ & $\begin{array}{c}\boldsymbol{\eta} \\
(\mathbf{e V})\end{array}$ & $\begin{array}{c}\boldsymbol{\sigma} \\
\left(\mathbf{e V}^{-\mathbf{1}}\right)\end{array}$ \\
\hline BF2 & -8.5988 & -3.6735 & 4.9253 & 6.4964 & 2.4626 & 0.4061 \\
\hline BF4 & -8.6532 & -4.8708 & 3.7824 & 4.4861 & 1.8912 & 0.5288 \\
\hline
\end{tabular}


The highest occupied molecular orbital ( $\mathrm{E}_{\text {номо }}$ ) and the lowest unoccupied molecular orbital $\left(\mathrm{E}_{\mathrm{LUMO}}\right)$ are very useful to elucidate the chemical reactivity of a molecule. According to the frontier molecular orbital theory of chemical reactivity, the transition of electrons is mainly related to the highest occupied molecular orbital (HOMO) and lowest unoccupied molecular orbital (LUMO) of the reacting species [55]. The HOMO is associated with the electron donation

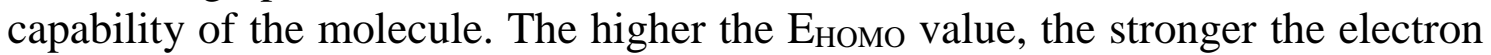
donating capability of the inhibitor will be and, therefore, the better the observed inhibition efficiency will be [56]. The LUMO implies the capability of the molecules to accept electrons from the metallic surface. The lower the value of ELUMO, the more it will be prone towards accepting electrons [57].

From Table 6, it can be concluded that the capability of donating electrons follows the order: BF4 > BF2. ELumo signifies the propensity of molecules to accept electrons. The lower value of the $\mathrm{E}_{\mathrm{LUMO}}$ is, the stronger is the ability of molecules to accept electrons. It can be observed (via Table 6) that the capability of accepting electrons obeys the order: BF2 > BF4. This is not in accordance with the result (inhibition efficiencies) obtained from the experiments.

The energy gap $(\Delta \mathrm{E})$ is a very important stability parameter of the molecules related to the reactivity tendency of the molecules towards the metal surface. The lower $\Delta \mathrm{E}$ is, the higher is the reactivity tendency of molecules in adsorption [58]. As for a molecule with lower energy gap, it means that the molecule is more polarizable and the molecule electrons are transported more smoothly. Thus, $\Delta \mathrm{E}$ has been used to measure the binding ability of molecules as an important index. It can be seen (via Table 6) that the property of molecules obeys the order: BF4 > BF2. These results are in good agreement with the experiments. Global softness $(\sigma)$ is also a predominant parameter to characterize the adsorption ability of molecules, and the higher the value is, the higher is the possibility of adsorption. In the research of corrosion inhibition chemistry, the inhibitors and the metals are considered as soft base and soft acid, respectively. It could be concluded (via Table 6) that the property of molecules obeys the order: BF4 > BF2. These results are in accordance to the former ones. The dipole moment $(\mu)$ of a molecule is also an important parameter to elucidate the chemical reactivity of a molecule. A literature survey reveals that the adsorption process is further facilitated with increased values of dipole moment as the latter influences the transport process through the adsorbed layer $[59,60]$. In this work it can be observed from Table 6 that the dipole moment values increase in the order of $\mathrm{BF} 4<\mathrm{BF} 2$, which is not in accordance with the experimental results.

\section{Active sites}

Inhibitor molecules are in general adsorbed on the metallic surface by the donor acceptor (D-A) type interaction between the inhibitor molecule and the concerned metallic surface. Therefore, it is essential to examine which corresponding active sites are responsible for this. Generally the more negative is the charge on the heteroatoms, more it can participate on the D-A type interactions [61]. However, it is also important to consider the situation from where the inhibitor molecules are going to receive certain amount of 
charges at some centres and reverting back for donating considerable amount of charges through consecutive centres [62]. This can be easily achieved by evaluating Fukui indices for each individual atom. This shows local reactivity as well as nucleophilic and electrophilic nature of the molecule [63]. Nucleophilic and electrophilic attacks are mainly controlled by the maximum threshold values of $f_{k}^{+}$and $f_{k}^{-} \cdot f_{k}^{+}$measures changes in electron density when the molecule accepts extra electrons, whereas $f_{k}^{-}$measures electron density changes when molecule loses electrons.

Table 7. Calculated Fukui functions for BF2 and BF4 molecules.

\begin{tabular}{|c|c|c|c|}
\hline Molecules & Atom & $f_{k}^{+}$ & $f_{k}^{-}$ \\
\hline \multirow[t]{11}{*}{ BF2 } & $1 \mathrm{C}$ & 0.175 & 0.004 \\
\hline & $2 \mathrm{C}$ & 0.019 & 0.165 \\
\hline & $10 \mathrm{~N}$ & 0.038 & 0.197 \\
\hline & $12 \mathrm{C}$ & 0.018 & 0.052 \\
\hline & $24 \mathrm{~N}$ & -0.028 & 0.018 \\
\hline & $25 \mathrm{C}$ & 0.088 & 0.125 \\
\hline & $26 \mathrm{C}$ & 0.156 & 0.126 \\
\hline & $27 \mathrm{C}$ & 0.032 & 0.152 \\
\hline & $45 \mathrm{~N}$ & 0.069 & 0.051 \\
\hline & $48 \mathrm{C}$ & 0.115 & 0.057 \\
\hline & $52 \mathrm{C}$ & 0.114 & 0.056 \\
\hline \multirow[t]{15}{*}{ BF4 } & $1 \mathrm{C}$ & 0.043 & 0.052 \\
\hline & $2 \mathrm{C}$ & 0.044 & 0.051 \\
\hline & $3 \mathrm{C}$ & 0.019 & 0.124 \\
\hline & $4 \mathrm{C}$ & 0.171 & 0.048 \\
\hline & $5 \mathrm{C}$ & 0.172 & 0.047 \\
\hline & $6 \mathrm{C}$ & 0.019 & 0.124 \\
\hline & $11 \mathrm{~N}$ & 0.039 & 0.207 \\
\hline & $13 \mathrm{C}$ & 0.121 & 0.064 \\
\hline & $25 \mathrm{~N}$ & -0.019 & 0.027 \\
\hline & $26 \mathrm{C}$ & 0.097 & 0.134 \\
\hline & $27 \mathrm{C}$ & 0.165 & 0.135 \\
\hline & $28 \mathrm{C}$ & 0.039 & 0.159 \\
\hline & $30 \mathrm{~N}$ & 0.078 & 0.063 \\
\hline & $49 \mathrm{C}$ & 0.124 & 0.066 \\
\hline & $53 \mathrm{C}$ & 0.123 & 0.065 \\
\hline
\end{tabular}

The calculated values of the Fukui functions for the non hydrogen atoms are reported in Table 7. From the results obtained, it can be stated that the site for nucleophilic attack is where the value of $f_{k}^{+}$is maximum. On the other hand, the site for electrophilic attack is controlled by the value of $f_{k}^{-}$.

It can be seen from Table 7 that in the BF2 molecule, the C(1), C(25), C(48) and $\mathrm{C}(53)$ atoms are the more susceptible sites for a nucleophilic attack (electron acceptance), as those atoms possess higher charge densities. On the other hand, the $\mathrm{C}(2), \mathrm{N}(10), \mathrm{C}(25), \mathrm{C}(26)$ and $\mathrm{C}(27)$ atoms mainly participate in the electrophilic attack (the donation of electrons). Therefore, it can be concluded from these results that all the individual atoms will participate in the D-A type interactions on the iron surface. On the other hand, C(4), C(5), C(13), C(27), $\mathrm{C}(49)$ and $\mathrm{C}(53)$ atoms are the favorable sites for electron acceptance, while the 
$\mathrm{C}(3), \mathrm{C}(6), \mathrm{C}(26), \mathrm{C}(27), \mathrm{C}(28)$ and $\mathrm{N}(11)$ atoms will be responsible for electron donation for BF4. Based on the above discussion, it can be concluded that BF2 and BF4 have many active sites for adsorption on the mild steel surface. These results are also in good accordance with experimentally obtained inhibition efficiency.

\section{Conclusion}

From the overall experimental results and theoretical calculations the following conclusions can be deduced:

- The synthesized tetrakis pyrazole derivatives showed good inhibition efficiencies for the corrosion of mild steel in $1.0 \mathrm{M} \mathrm{HCl}$ solution, and the inhibition efficiency increased on increasing the concentration of inhibitor. The inhibiting performance of $\mathrm{BF} 4$ is better than that of $\mathrm{BF} 2$.

- Inhibition efficiency $\left(\eta_{W_{L}}\right)$ decreases with the temperature. The value of apparent activation energy $\left(\mathrm{E}_{\mathrm{a}}\right)$ in the presence of inhibitors is higher than that in the absence of inhibitor.

- The adsorption of each tetrakis pyrazole inhibitor obeys Langmuir adsorption isotherm.

- Polarization studies showed that both tested inhibitors are mixed type in nature.

- Electrochemical impedance spectroscopy (EIS) measurements show that charge transfer resistance $\left(\mathrm{R}_{\mathrm{ct}}\right)$ increases and double-layer capacitance $\left(\mathrm{C}_{\mathrm{dl}}\right)$ decreases in presence of inhibitors, suggesting the adsorption of the inhibitor molecules on the surface of mild steel.

- Quantum chemical calculations reveal that the electron donation and electron acceptance capabilities of the studied inhibitors follow the order BF4 > BF2, which is in good accordance with the results obtained from previously performed experiments.

- The active sites of the studied inhibitor molecules are also thoroughly investigated using Fukui indices. Fukui indices describe in detail which particular atoms mainly participate for the electron donation and acceptance processes between the inhibitors and the Fe surface.

\section{References}

1. Sastri VS. Corrosion Inhibitors - Principles and Applications. Chichester, England: Wiley; 1998.

2. Lagrenee M, Mernari B, Bouanis M, et al. Study of the mechanism and inhibiting efficiency of 3,5-bis(4-methylthiophenyl)-4H-1,2,4-triazole on mild steel corrosion in acidic media. Corros Sci. 2002;44:573-588.

3. Abdallah M. Ethoxylated fatty alcohols as corrosion inhibitors for dissolution of zinc in hydrochloric acid. Corros Sci. 2003;45:2705-2716.

4. Naik UJ, Panchal VA, Patel AS, et al. The corrosion inhibition study of Al Pure By p-Anisidine -N-Benzylidene Schiff base in $\mathrm{HCl}$ solution. J Mater Environ Sci. 2012;3:935-946.

5. Al Hamzi AH, Zarrok H, Zarrouk A, et al. The Role of Acridin-9(10H)-one 
in the Inhibition of Carbon Steel Corrosion: Thermodynamic, Electrochemical and DFT Studies. Int J Electrochem Sci. 2013;8:25862605.

6. Zarrouk A, Hammouti B, Zarrok H, et al. N-containing organic compound As An Effective Corrosion Inhibitor For Copper In $2 \mathrm{M} \mathrm{HNO}_{3}$ : Weight Loss and Quantum Chemical Study. Der Pharm Chem. 2011;3:263-271.

7. Ghazoui A, Bencaht N, Al-Deyab SS, et al. An Investigation of Two Novel Pyridazine Derivatives as Corrosion Inhibitor for C38 Steel in $1.0 \mathrm{M} \mathrm{HCl}$. Int J Electrochem Sci. 2013;8:2272-2292.

8. Zarrouk A, Zarrok H, Salghi R, et al. The Adsorption and Corrosion Inhibition of 2-[Bis-(3,5-dimethyl-pyrazol-1-ylmethyl)-amino]pentanedioic Acid on Carbon Steel Corrosion in $1.0 \mathrm{~m} \mathrm{HCl}$. Int J Electrochem Sci. 2012;7:10215-10232.

9. Zarrouk A, Hammouti B, Zarrok H, et al. Corrosion Inhibition of Copper in Nitric Acid Solutions Using a New Triazole Derivative. Int J Electrochem Sci. 2012;6:89-105.

10. Ghazoui A, Saddik R, Benchat N, et al. Comparative Study of Pyridine and Pyrimidine Derivatives as Corrosion Inhibitors of C38 Steel in Molar HCl. Int J Electrochem Sci. 2012;7:7080-7097.

11. Quraishi MA, Sardar R, Jamal D. Corrosion inhibition of mild steel in hydrochloric acid by some aromatic hydrazides. Mater Chem Phys. 2001;71:309-313.

12. El Ouali I, Chetouani A, Hammouti B, et al. Thermodynamic Study and Characterization by Electrochemical Technique of Pyrazole Derivatives as Corrosion Inhibitors for C38 Steel in Molar Hydrochloric Acid. Port Electrochim Acta. 2013;31:53-78.

13. Eddy NO, Ameh PO, Gwarzo MY, et al. Physicochemical Study and Corrosion Inhibition Potential of Ficus tricopoda for Aluminium in Acidic Medium. Port Electrochim Acta. 2013;31:79-93.

14. Joseph B, Prajila M, Joseph A. Inhibition of Mild Steel Corrosion in $1 \mathrm{M}$ Hydrochloric Acid Using (E)-(4-(4-methoxybenzylideneamino)-4H-1, 2, 4triazole-3, 5-diyl) Dimethanol (MBATD). J Dispersion Sci Technol. 2012;33:739-749.

15. Kabanda MM, Murulana LC, Ozcan M, et al. Quantum Chemical Studies on the Corrosion Inhibition of Mild Steel by Some Triazoles and Benzimidazole Derivatives in Acidic Medium. Int J Electrochem Sci. 2012;7:5035-5056.

16. Zertoubi M, Zerouali D, Hammouti B, et al. The Inhibitive Effect of 2Phenyl-3-nitroso-imidazo [1, 2-a]pyridine on the Corrosion of Steel in 0.5 M HCl Acid Solution. E-J Chem. 2010;7:S35-S42.

17. Khaled KF, Abdel-Rehim SS, Sakr GB. On the corrosion inhibition of iron in hydrochloric acid solutions, Part I: Electrochemical DC and AC studies. Arab J Chem. 2012;5:213-218.

18. Ogukwe CE, Akalezi CO, Chidiebere MA, et al. Corrosion Inhibition and Adsorption of Anthocleista Djalonesis Leaf Extract on the Acid Corrosion of Mild Steel. Port Electrochim Acta. 2012;30:189-202. 
19. Khaled KF, Abdel-Rehim SS. Electrochemical investigation of corrosion and corrosion inhibition of iron in hydrochloric acid solutions. Arab $\mathbf{J}$ Chem. 2011;4:397-402.

20. Tebbji K, Aouniti A, Attayibat A, et al. Inhibition efficiency of two bipyrazole derivatives on steel corrosion in hydrochloric acid media. Indian J Chem Technol. 2011;18:244-253.

21. Hammouti B, Dafali A, Touzani R, et al. Inhibition of copper corrosion by bipyrazole compound in aerated 3\% NaCl. J Saudi Chem Soc. 2012;16:413418.

22. Zarrok H, Oudda H, El Midaoui A, et al. Some new bipyrazole derivatives as corrosion inhibitors for C38 steel in acidic medium. Res Chem Intermed. 2012;38:2051-2063.

23. Tebbji K, Oudda H, Hammouti B, et al. The effect of 1',3,5,5'-tetramethyl$1^{\prime} \mathrm{H}-1,3^{\prime}$-bipyrazole on the corrosion of steel in 1.0 M hydrochloric acid. Res Chem Intermed. 2011;37:985-1007.

24. Bendaha H, Zarrouk A, Aouniti A, et al. Adsorption and corrosion inhibitive properties of some tripodal pyrazolic compounds on mild steel in hydrochloric acid systems. Phys Chem News. 2012;64:95-103.

25. Zarrok H, Al Mamari K, Zarrouk A, et al. Gravimetric and Electrochemical Evaluation of 1-allyl-1Hindole-2,3-dione of Carbon Steel Corrosion in Hydrochloric Acid. Int J Electrochem Sci. 2012;7:10338-10357.

26. Zarrok H, Zarrouk A, Salghi R, et al. 3,7-Dimethylquinoxalin-2-(1H)-one for inhibition of acid corrosion of carbon steel. J Chem Pharm Res. 2012;4:5048-5055.

27. Belayachi M, Serrar H, Zarrok H, et al. New pyrimidothiazine Derivative as Corrosion Inhibitor for Carbon Steel in Acidic Media. Int J Electrochem Sci. 2015;10:3010-3025.

28. Tayebi H, Bourazmi H, Himmi B, et al. An electrochemical and theoretical evaluation of new quinoline derivative as a corrosion inhibitor for carbon steel in $\mathrm{HCl}$ solutions. Der Pharm Lett. 2014;6:20-34.

29. Tayebi H, Bourazmi H, Himmi B, et al. Combined electrochemical and quantum chemical study of new quinoxaline derivative as corrosion inhibitor for carbon steel in acidic media. Der Pharm Chem. 2014;6:220234.

30. Zarrok H, Zarrouk A, Salghi R, et al. Inhibitive properties and thermodynamic characterization of quinoxaline derivative on carbon steel corrosion in acidic medium. Der Pharm Lett. 2013;5:43-53.

31. ASTM Designation G1-03 "Standard Practice for Preparing, Cleaning, and Evaluating Corrosion Test Specimens"; 2011.

32. Gaussian 03, Revision B.01, M. J. Frisch, et al., Gaussian, Inc., Pittsburgh, PA, 2003.

33. Hehre WJ, Radom L, Schleyer PVR, et al. AB INITIO Molecular Orbital Theory. New York: Wiley-Interscience; 1986.

34. Janak JF. Proof that $\partial E / \partial n_{i}=\varepsilon$ in density-functional theory. Phys Rev B. 1978;18:7165-7168.

35. Stowasser R, Hoffmann R. What Do the Kohn-Sham Orbitals and Eigenvalues Mean? J Am Chem Soc. 1999;121:3414-3420. 
36. Pearson RG. Absolute electronegativity and hardness: application to inorganic chemistry. Inorg Chem. 1988;27:734-740.

37. Parr RG, Yang W. Density functional approach to the frontier-electron theory of chemical reactivity. J Am Chem Soc. 1984;106:4049-4050.

38. Khaled KF. Studies of iron corrosion inhibition using chemical, electrochemical and computer simulation techniques. Electrochim Acta. 2010;55:6523-6532.

39. Fouda AS, Elewady YA, Abd El-Aziz HK. Corrosion inhibition of carbon steel by cationic surfactants in $0.5 \mathrm{M} \mathrm{HCl}$ solution. J Chem Sci Technol. 2012;1:45-53.

40. Li X, Deng S, Fu H, et al. Inhibition effect of 6-benzylaminopurine on the corrosion of cold rolled steel in $\mathrm{H}_{2} \mathrm{SO}_{4}$ solution. Corros Sci. 2009;51:620634.

41. Amar H, Tounsi A, Makayssi A, et al. Corrosion inhibition of Armco iron by 2-mercaptobenzimidazole in sodium chloride $3 \%$ media. Corros Sci. 2007;49:2936-2945.

42. Deyab MA, Abd El-Rehim SS, Keera ST. Study of the effect of association between anionic surfactant and neutral copolymer on the corrosion behavior of carbon steel in cyclohexane propionic acid. Colloids Surf A. 2009;348:170-176.

43. Haruyama S, Tsuru T, Gijutsu B. Corrosion inhibition of iron by amphoteric surfactants in 2M HCl. J Jpn Soc Corros Eng. 1978;27:573-581.

44. Elkadi L, Mernari B, Traisnel M, et al. The inhibition action of 3,6-bis(2methoxyphenyl)-1,2-dihydro-1,2,4,5-tetrazine on the corrosion of mild steel in acidic media. Corros Sci. 2000;42:703-719.

45. Saliyan VR, Adhikari AV. Quinolin-5-ylmethylene-3-\{[8-(trifluoromethyl) quinolin-4-yl]thio \}propanohydrazide as an effective inhibitor of mild steel corrosion in $\mathrm{HCl}$ solution. Corros Sci. 2008;50:55-61.

46. Atta AM, El-Azabawy OE, Ismail HS, et al. Novel dispersed magnetite core-shell nanogel polymers as corrosion inhibitors for carbon steel in acidic medium. Corros Sci. 2011;53:1680-1689.

47. Bockris JO'M, Reddy AKN. Modern Electrochemistry. New York: Plenum Press; 1977. P. 1267.

48. Bentiss F, Lebrini M, Lagrenée M. Thermodynamic characterization of metal dissolution and inhibitor adsorption processes in mild steel/2,5-bis(nthienyl)-1,3,4-thiadiazoles/hydrochloric acid system. Corros Sci. 2005;47:2915-2931.

49. Dehri I, Özcan M. The effect of temperature on the corrosion of mild steel in acidic media in the presence of some sulphur containing organic compounds. Mater Chem Phys. 2006;98:316-323.

50. Gomma GK, Wahdan MH. Schiff bases as corrosion inhibitors for aluminium in hydrochloric acid solution. Mater Chem Phys. 1995;39:209-213.

51. Guan NM, Xueming L, Fei L. Synergistic inhibition between ophenanthroline and chloride ion on cold rolled steel corrosion in phosphoric acid. Mater Chem Phys. 2004;86:59-68.

52. Li X, Deng $\mathrm{S}, \mathrm{Fu} \mathrm{H}$, et al. Synergistic inhibition effect of rare earth 
cerium(IV) ion and anionic surfactant on the corrosion of cold rolled steel.Corros. Sci. 2008;50:2635-2645.

53. Abdallach M. Rhodanine azosulpha drugs as corrosion inhibitors for corrosion of 304 stainless steel in hydrochloric acid solution. Corros Sci. 2002;44:717-728.

54. Noor EA. Temperature Effects on the Corrosion Inhibition of Mild Steel in Acidic Solutions by Aqueous Extract of Fenugreek Leaves. Int $\mathbf{J}$ Electrochem Sci. 2007;2:996-1017.

55. Özkır D, Kayakırılmaz K, Bayol E, et al. The inhibition effect of Azure A on mild steel in $1 \mathrm{M} \mathrm{HCl}$. A complete study: Adsorption, temperature, duration and quantum chemical aspects. Corros Sci. 2012;56:143-152.

56. Obi-Egbedi NO, Obot IB. Inhibitive properties, thermodynamic and quantum chemical studies of alloxazine on mild steel corrosion in $\mathrm{H}_{2} \mathrm{SO}_{4}$, Corros Sci. 2011;53:263-275.

57. Khaled KF. Adsorption and inhibitive properties of a new synthesized guanidine derivative on corrosion of copper in $0.5 \mathrm{M} \mathrm{H}_{2} \mathrm{SO}_{4}$. Appl Surf Sci. 2008;255:1811-1818.

58. El Adnani Z, McHarfi M, Sfaira M, et al. DFT theoretical study of 7-R3 methylquinoxalin-2 $(1 \mathrm{H})$-thiones $\left(\mathrm{RH} ; \mathrm{CH}_{3} ; \mathrm{Cl}\right)$ as corrosion inhibitors in hydrochloric acid. Corros Sci. 2013;68:223-230.

59. Sahin M, Gece G, Karci F, et al. Experimental and theoretical study of the effect of some heterocyclic compounds on the corrosion of low carbon steel in 3.5\% NaCl medium. J Appl Electrochem. 2008;38:809-815.

60. Quraishi MA, Sardar R. Hector bases-a new class of heterocyclic corrosion nhibitors for mild steel in acid solutions. J Appl Electrochem. 2003;33:1163-1168.

61. Gece G, Bilgiç S, Molecular-level understanding of the inhibition efficiency of some inhibitors of zinc corrosion by quantum chemical approach. Ind Eng Chem Res. 2012;51:14115-14120.

62. Breket G, Hur E, Ogretir C. Quantum chemical studies on some imidazole derivatives as corrosion inhibitors for iron in acidic medium. J Mol Struct (Theochem). 2002;578:79-88.

63. Shokry H. Molecular dynamics simulation and quantum chemical calculations for the adsorption of some Azo-azomethine derivatives on mild steel. J Mol Struc. 2014;1060:80-87.

64. Hegazy MA, Badawi AM, Abd El Rehim SS, et al. Corrosion inhibition of carbon steel using novel N-(2-(2-mercaptoacetoxy)ethyl)-N,N-dimethyl dodecan-1-aminium bromide during acid pickling. Corros Sci. 2013;69:110-122. 